\title{
Técnica Alternativa para Montagem de Insetos em Lâminas Permanentes para Visualização em Microscopia Óptica
}

\author{
Franziska Huber ${ }^{1 \bowtie}$ \& Fernanda Helena dos Reis ${ }^{2}$
}

1. Instituto Superior de Tecnologia de Paracambi (FAETEC), Laboratório de Monitoramento Ambiental, Curso de tecnologia em Gestão Ambiental, e-mail: franziska.huber@gmail.com (Autor para correspondência ${ }^{\bowtie}$ ). 2. Instituto Superior de Tecnologia de Paracambi, e-mail: fernandahelenareis@gmail.com

\author{
EntomoBrasilis 4 (1): 13-19 (2011)
}

Resumo. Diversas substâncias químicas são utilizadas na montagem de insetos em lâminas permanentes para visualização em microscopia óptica. $\mathrm{O}$ alto custo, a indisponibilidade no comércio convencional e a periculosidade de tais substâncias químicas, fazem com que este meio de estudo prático torne-se pouco viável para alguns estudos didáticos. Dentre os diversos produtos químicos utilizados para a montagem de insetos em lâminas permanentes os mais utilizados são o xilol, bálsamo do Canadá, hidróxido de potássio, alcoóis, fenol, creosoto, entre outros. Todos estes produtos químicos apresentam, individualmente ou em conjunto, alguns riscos para a saúde humana. Com a finalidade de encontrar materiais alternativos, de fácil acesso e baixa toxicidade para a montagem de insetos em lâminas permanentes para microscopia, o presente estudo testou a eficiência de algumas substâncias alternativas. Foram testados: verniz vitral incolor (Acrilex®) como substituto do bálsamo do Canadá e solvente para artesanato (Acrilex®), Óleo de imersão (Merck $囚)$ e xilol em substituição ao creosoto de Faia. Foram realizadas montagens de Ctenocephalides sp., de Aedes aegypti (Linnaeus) e Pediculus sp.. O uso de verniz vitral incolor mostrou ser um substituto barato e eficiente ao Bálsamo do Canadá, oferecendo ótima transparência e visualização, além de rápida secagem. O óleo de imersão pôde ser utilizado em substituição ao creosoto de Faia, tanto para montagens em bálsamo, quanto em verniz, sendo que a última combinação apresentou vantagens, devido à rapidez da secagem do verniz. $\mathrm{O}$ solvente para artesanato não obteve bons resultados aparentando agredir demasiadamente a quitina dos insetos, efeito observado principalmente quando em combinação com o verniz vitral.

Palavras-chave: Microscopia; montagem de insetos; óleo; solvente; verniz

\section{Alternative Permanent Slide Mounting Technique of Insects for Light Microscopy}

Abstract. Various chemicals are used in the mounting of insects on permanent slides for optical microscopy. The high cost, little availability in ordinary commerce and the dangers make their use impractical for some studies. Among the various chemicals used for the microscopic mounting of insects are Xylene, Canada Balsam, Hydroxide Potassium, Alcohols, Phenol and Creosote. All these chemicals present, individually or collectively, some risks to human health. In order to find alternative materials of easy access and low toxicity, for the permanent mout of insects, this study tested

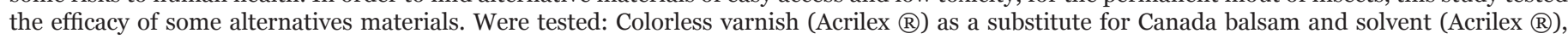
Immersion Oil for microscopy (Merck $($ ) ) and Xylene as substitutes for creosote. There were mounted especimens of Ctenocephalides sp., Aedes aegypti (Linnaeus) and Pediculus sp.. The use of Varnish Colorless proved to be an efficient and cheap substitute to Canada Balsam because it offered transparency, optimal visualization, and rapid drying. The immersion oil might be used instead of Creosote, both mounted in Balsam, as in varnish. The last combination was more advantageous due to rapid drying of the varnish. Solvent did not get good results appearing to damage insect chitin, an effect observed especially when combined with the varnish.

Keywords: Microscopy; oil; permanent mount of insects; solvent; varnish

A microscopia óptica é ferramenta essencial no estudo das mais diversas áreas na medicina, botânica, parasitologia, microbiologia, entre outras. Porém, dificilmente as amostras a serem analisadas ao microscópio podem ser utilizadas sem preparos específicos, que as tornem aptas à passagem da luz, ou na ausência de corantes específicos, que evidenciam determinadas estruturas.

Considerando especificamente o estudo de insetos pela microscopia óptica, deve ser levado em consideração que estes possuem um exoesqueleto de quitina, normalmente firme e pigmentado, o que pode inviabilizar um exame acurado da morfologia de algumas espécies. Por outro lado, para o exame microscópico, o espécime deve ser montado sobre uma lâmina de vidro e coberto com uma lamínula, também de vidro. No caso de espécimes de grande volume, pode surgir um espaço entre lâmina e lamínula, que deve ser preenchido com alguma substância que permita a passagem da luz, sem desviá-la, permitindo assim a visualização correta das estruturas.

Segundo Cerqueira (1943), vários meios e fixadores são empregados nas preparações microscópicas destinadas ao estudo dos mosquitos em suas diferentes partes ou fases de desenvolvimento, bem como de outros pequenos dípteros. Dentre eles o Bálsamo do Canadá é o de uso mais comum.

Muitas técnicas de preparação têm sido utilizadas com graus diversos de sucesso. Algumas delas, embora muito convenientes inicialmente, não resistem ao teste do tempo. Isto levou à publicação da "Técnica Básica em Bálsamo do Canadá", usado por muitos entomologistas ao longo de décadas, na esperança de que ele irá facilitar a padronização de resultados pelos trabalhadores nesta área (PALMA 1978).

Apesar das diferenças, a sequência do procedimento geralmente inicia-se pelo processo de clarificação, desidratação 
e diafanização. Para a clarificação comumente são usados o hidróxido de potássio $(\mathrm{KOH})$, fenol e o lactofenol. O álcool etílico, em diferentes concentrações, é utilizado na desidratação dos insetos. Para diafanização, o xilol e o creosoto são bastante empregados, enquanto que a montagem permanente pode ser implementada com uso de bálsamo do Canadá.

Diretamente proporcional à complexidade e ao grau de toxicidade destes produtos, está a disponibilidade dos mesmos e seu custo para o mercado consumidor. Alguns dos produtos descritos têm custos elevados, diminuindo a possibilidade de obtenção dos mesmos por profissionais técnicos, professores e alunos de instituições menos abastadas. Alguns também possuem a comercialização controlada, pois, em sua maioria, estes produtos não são comercializados no mercado comum e só podem ser comprados diretamente da indústria química produtora, onde ainda pode ser exigida a apresentação de alguns documentos legais, tais como registro no Conselho Regional de Química; cadastro e autorização da Polícia Federal; documentos comprobatórios da instituição que está adquirindo; entre outros, assim como a contratação de transporte apropriado, não sendo permitido o transporte em coletivos ou em veículos particulares comuns. Além do mais, as indústrias químicas estipulam um faturamento mínimo para venda.

As dificuldades encontradas para a obtenção destes produtos, proveniente de políticas e regras impostas devido à periculosidade das substâncias, é facilmente compreensível, uma vez que são necessárias medidas de segurança para a sua comercialização.

Devido a certas dificuldades na obtenção destes materiais e visando a redução dos custos de produção de lâminas permanentes, PaIva et al. (2006) testou meios alternativos para a montagem de lâminas com tecidos vegetais. Foram escolhidos produtos produzidos por empresas brasileiras, principalmente para uso em artesanato. Entre os diferentes meios sintéticos testados, o verniz vitral incolor $500 \AA$ demonstrou propriedades compatíveis para o uso eficiente como meio de montagem, em substituição às resinas sintéticas importadas, com custo baixo e sem alteração do processo rotineiro de trabalho. No estudo citado, o verniz vitral incolor $500 \AA$ permitiu a montagem de lâminas permanentes com órgãos seccionados a mão livre ou em micrótomo rotatório, após o emblocamento em parafina ou historresina, mantendo inalteradas as características dos materiais vegetais e da coloração. Os resultados evidenciaram que os meios de montagem tradicionais podem ser substituídos pelo verniz vitral incolor $500 \AA$, sem comprometimento da qualidade das lâminas.

Existem numerosas técnicas de montagem descritas, por vezes diferenciadas para as diversas estruturas. A técnica descrita apresentada em Consolı et al. (1994) é a mais comumente relatada para a montagem de insetos em bálsamo do Canadá:

1. Clarificação A - solução de $\mathrm{KOH}$ a 10\%, fria, durante 12 horas (apenas para materiais fortemente quitinizados).

2. Desidratação: álcool 70\% - 15 minutos; álcool $80 \%-15$ minutos; álcool 90\% - 15 minutos; álcool 95\% - 10 minutos; álcool absoluto -10 minutos.

3. Clarificação B - creosoto de faia - 24 horas.

4. Montagem - com bálsamo do Canadá, entre lâmina e lamínula.

5. Secagem - preferencialmente em estufa, a $40-45^{\circ} \mathrm{C}$, o que favorece a eliminação de eventuais pequenas bolhas de ar.

Outra técnica de montagem de lâminas permanentes de insetos é descrita por CARDOSO (2009). De acordo com o autor: "Durante a clarificação os insetos são colocados em pequenas placas de Petri numa solução de hidróxido de potássio ( $\mathrm{KOH}$ a 10\%), onde permanecem entre 2-3 horas para que haja o amolecimento da quitina, após esse período são transferidos para outras placas de Petri com ácido acético, por um período de 15-20 minutos para retirar o excesso de hidróxido de potássio, a seguir lava-se em água destilada por 20 minutos. Os insetos permanecem em lactofenol por 24 horas, para diafanizar, em seguida são montados entre lâmina e lamínula, em líquido de Berlese, e as lâminas colocadas para secar horizontalmente.”

O objetivo deste estudo foi encontrar materiais alternativos para montagem de insetos em lâminas para microscopia, utilizando produtos que ofereçam resultados satisfatórios commenor custo demercado, facilmenteencontrados no comércio e que possuam menor grau de nocividade à saúde humana e ao ambiente.

Especificamente propomos testar a substituição do creosoto pelo óleo de imersão (Merck®), xilol e solvente de artesanato (Acrilex@) e a substituição da utilização do bálsamo do Canadá pelo verniz vitral incolor (Acrilexß).

\section{MATERIAL E MÉTODOS}

Para testar os diferentes produtos químicos e estabelecer um protocolo alternativo de montagem de insetos, foram utilizadas espécimes de pulgas (Ctenocephalides sp.), mosquitos (Aedes aegypti Linnaeus) e piolhos (Pediculus sp.).

O protocolo base proposto por Consoli et al. (1994) foi seguido segundo descrito abaixo:

1. Clarificação dos espécimes em solução de $\mathrm{KOH} 2 \%$, por tempo variável, de acordo com a quitinização do espécime;

2. Desidratação em soluções de álcool etílico, iniciando com álcool $70^{\circ}$, passando pelas concentrações de $80^{\circ}, 90^{\circ} \mathrm{e}$ álcool etílico absoluto. Os espécimes ficaram 10 minutos em cada uma das etapas.

Estes procedimentos foram iguais para todos os espécimes. Após a desidratação as amostras foram submetidas a diferentes procedimentos. testadas:

As seguintes variações da técnica original foram

a) Óleo de imersão Merck® por 10 minutos e montagem em bálsamo do Canadá - 3 pulgas/2 piolhos/2 mosquitos;

b) Óleo de imersão Merck® por 20 minutos e montagem em bálsamo do Canadá - 2 pulgas;

c) Óleo de imersão Merck® por 10 minutos e montagem em verniz vitral incolor -3 pulgas/1 piolho/1 mosquito;

d) Óleo de imersão Merck® por 20 minutos e montagem em verniz vitral incolor -2 pulgas.

Totalizando 16 lâminas que utilizaram óleo de imersão em lugar do creosoto e testando sua adequação ao bálsamo do Canadá ou ao verniz vitral incolor.

a) Xilol a 10 minutos e montagem em bálsamo do Canadá - 2 pulgas/1 piolho/1 mosquito;

b) Xilol a 20 minutos e montagem em bálsamo do Canadá - 2 pulgas;

c) Xilol a 10 minutos e montagem em verniz vitral incolor -2 pulgas/2 piolhos;

d) Xilol a 20 minutos e montagem em verniz vitral incolor -2 pulgas.

Totalizando 12 lâminas utilizando-se o xilol em substituição ao creosoto e testando sua adequação ao bálsamo do Canadá ou ao verniz vitral incolor.

a) Solvente a 10 minutos e montagem em bálsamo do Canadá -2 pulgas/1 piolho;

b) Solvente a 20 minutos e montagem em bálsamo do Canadá -2 pulgas;

c) Solvente a 10 minutos e montagem em verniz vitral incolor -2 pulgas/1 piolho;

d) Solvente a 20 minutos e montagem em verniz vitral incolor -2 pulgas.

Totalizando 10 lâminas utilizando-se o solvente para artesanato em substituição ao creosoto e testando sua adequação ao bálsamo do Canadá ou ao verniz vitral incolor.

O registro fotográfico foi realizado utilizando uma câmera Olympus DP 25 acoplada ao microscópio óptico Olympus 
BX51. Os softwares de captura e edição de imagem são ImagePro plus, versão 6,3 para Windows e o DP2-BSW da Olympus.

As lâminas montadas foram analisadas e fotografadas em microscópio óptico, imediatamente após a montagem e depois semanalmente nas quatro primeiras semanas. Posteriormente as lâminas foram guardadas e reexaminadas após 10 meses.

\section{RESULTADOS E DISCUSSÃO}

Das 37 lâminas montadas, duas tiveram que ser descartadas por erros na montagem, restando 35 lâminas montadas com aproveitamento.

A maioria das lâminas apresentou boa ou ótima condição de visualização em microscopia. Desde o dia da montagem, e até 10 meses após, algumas lâminas mantiveram-se inalteradas e algumas apresentaram melhora nas condições de visualização.

Observando-se as lâminas onde foi utilizado o óleo de imersão, em substituição ao creosoto, em montagens com bálsamo do Canadá e verniz vitral incolor, constatou-se que, no primeiro momento, as montagens feitas com óleo e verniz apresentaram resultados mais satisfatórios em comparação com as montagens feitas com óleo e bálsamo, pois as mesmas apresentaram bolhas no interior dos insetos e no espaço ao redor destes, além de manchas do óleo (Figura 1). Estes aspectos desapareceram no decorrer do tempo, não sendo mais visualizadas após 35 dias de montagem (Figura 2).

Na Figura 3 pode ser visualizada a evolução ao longo do tempo, das lâminas nas quais foi utilizado óleo de imersão em substituição ao creosoto e montagem em bálsamo do Canadá ou verniz vitral. O tempo de permanência do inseto no óleo de imersão antes à montagem, não exerceu diferença para o resultado final da montagem, de forma que tais fotografias não foram aqui expostas.

A evolução da visibilidade das montagens de mosquitos, utilizando xilol em substituição ao creosoto e montagem em Bálsamo do Canadá ou Verniz Vitral, pode ser melhor avaliada na figura 4 enquanto que as mesmas técnicas aplicadas à montagem de pulgas podem ser avaliadas na Figura 5 .

Na Figura 6 são mostrados os resultados da substituição do creosoto por solvente para artesanato e montagem em bálsamo do Canadá ou verniz vitral.

Quanto aos meios de montagem utilizados, observou-se que mesmo após 10 meses, e independentemente da utilização do xilol, óleo de imersão ou do solvente, as lâminas montadas em bálsamo do Canadá não apresentaram-se completamente secas, ocorrendo mudanças na disposição do inseto. Na Figura $4 \mathrm{C}$ pode ser observado a ocorrência de um artefato grave, pois as lâminas haviam sido deixadas na horizontal, dispostas em bandejas, por dois meses, após os quais foram enroladas em papel earmazenadas em armário, já que aparentavam estar secas. Como o bálsamo não havia secado completamente, houve extravasamento deste com consequente entrada de ar entre lâmina e lamínula. Não houve problemas de secagem das lâminas montadas em verniz vitral, que apresentou secagem completa em 24 horas.

As lâminas montadas com solvente para artesanato, em substituição ao creosoto, também obtiveram boa visualização no microscópio, tanto nas montagens com bálsamo do Canadá, quanto com verniz vitral incolor. Porém, observou-se que o

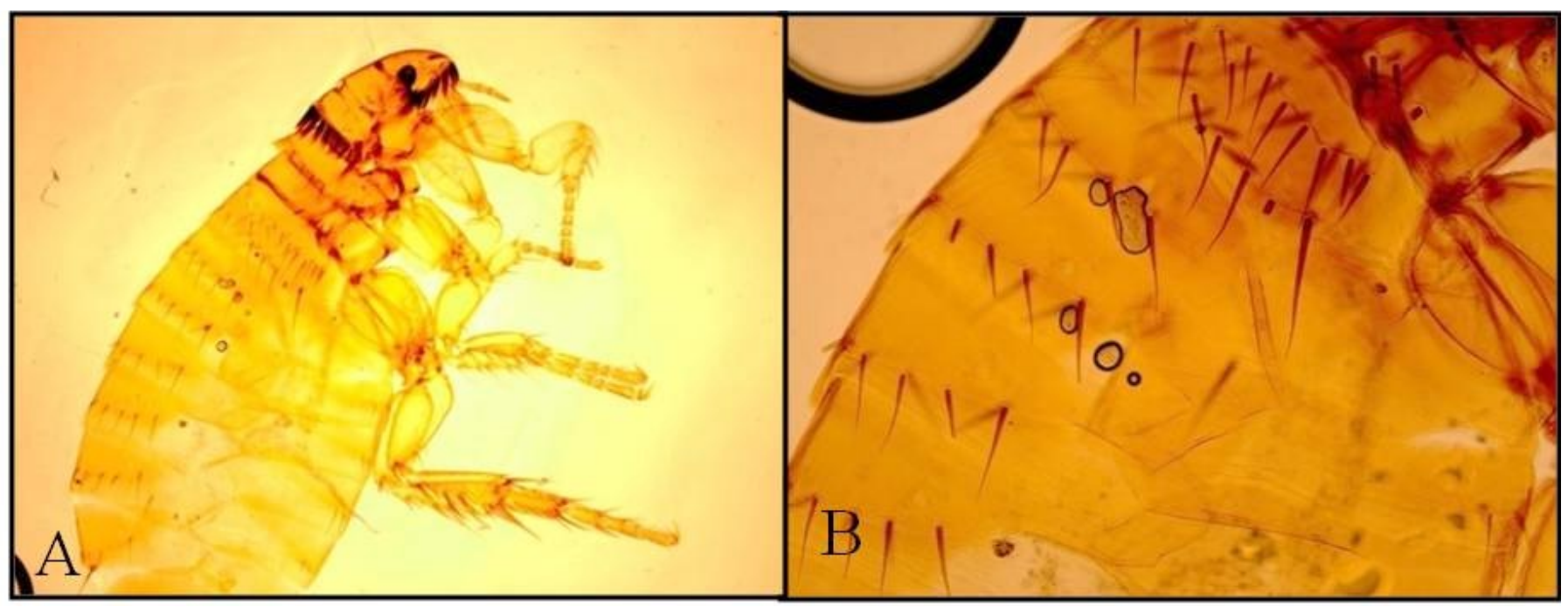

Figura 01. Lâmina 02, montagem em óleo de imersão e bálsamo do Canadá. A) Objetiva de 4x; B) Objetiva de 10x. Fotografada logo após a montagem - Note a presença de bolhas no interior e ao redor do inseto.

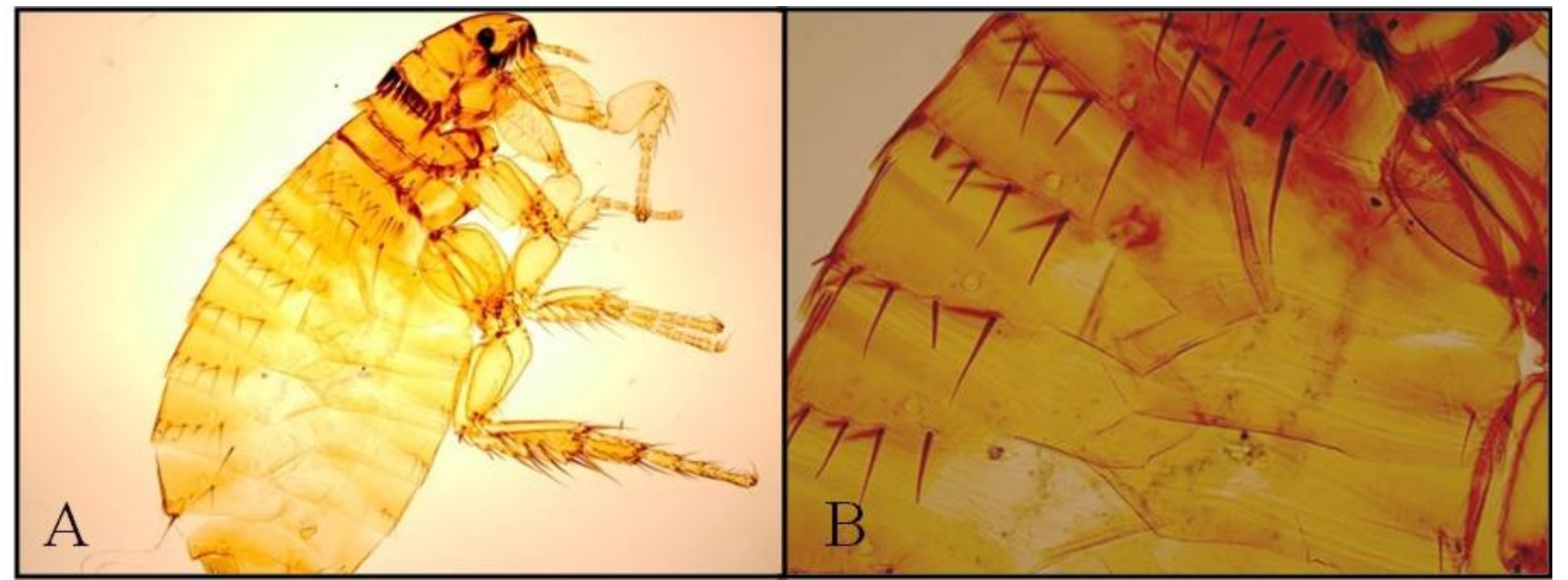

Figura 02. Lâmina 02, montagem em óleo de imersão e bálsamo do Canadá. A) Objetiva de 4x; B) Objetiva de 10x. Fotografada 35 dias após a montagem - Note a ausência das bolhas ao redor e dentro do inseto. 


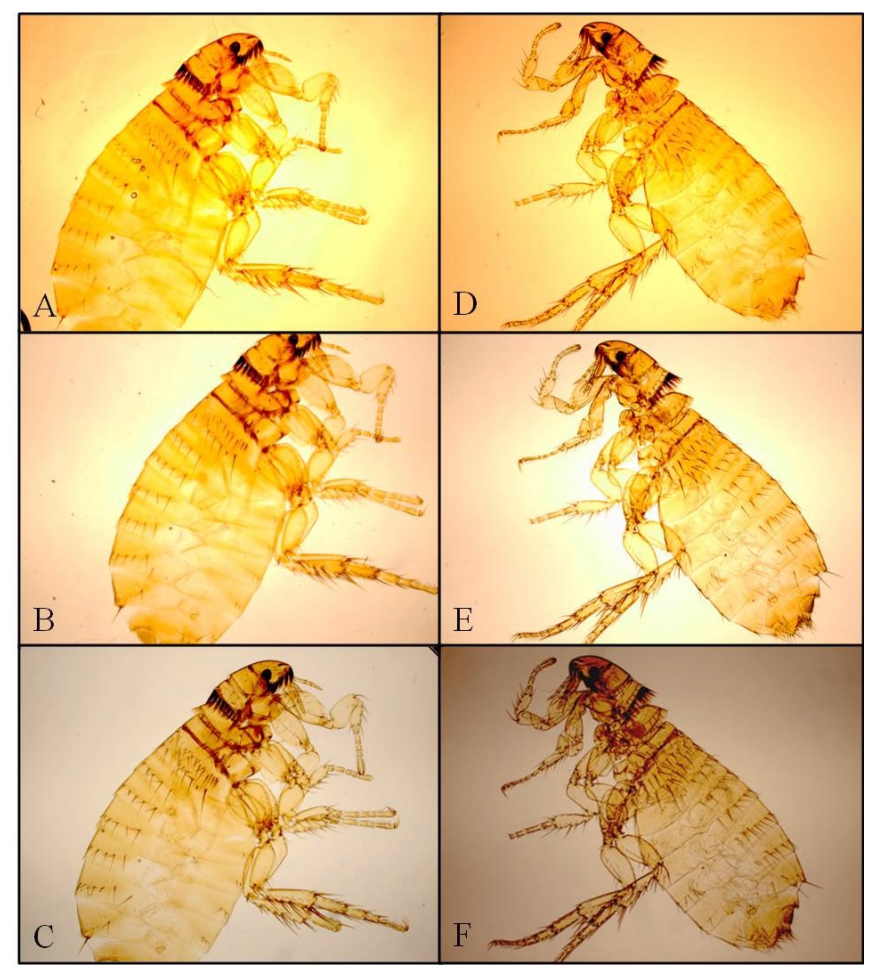

Figura 03. A) a C) Lâmina 02, montagem em óleo de imersão e bálsamo do Canadá. Objetiva de 4x. A) Imediatamente após a montagem; B) 07 dias após a montagem; C) 10 meses após a montagem. D) a F) Lâmina 04, montagem em óleo de imersão e verniz vitral. Objetiva de 4x. D) Imediatamente após a montagem; E) 07 dias após a montagem; F) 10 meses após a montagem.

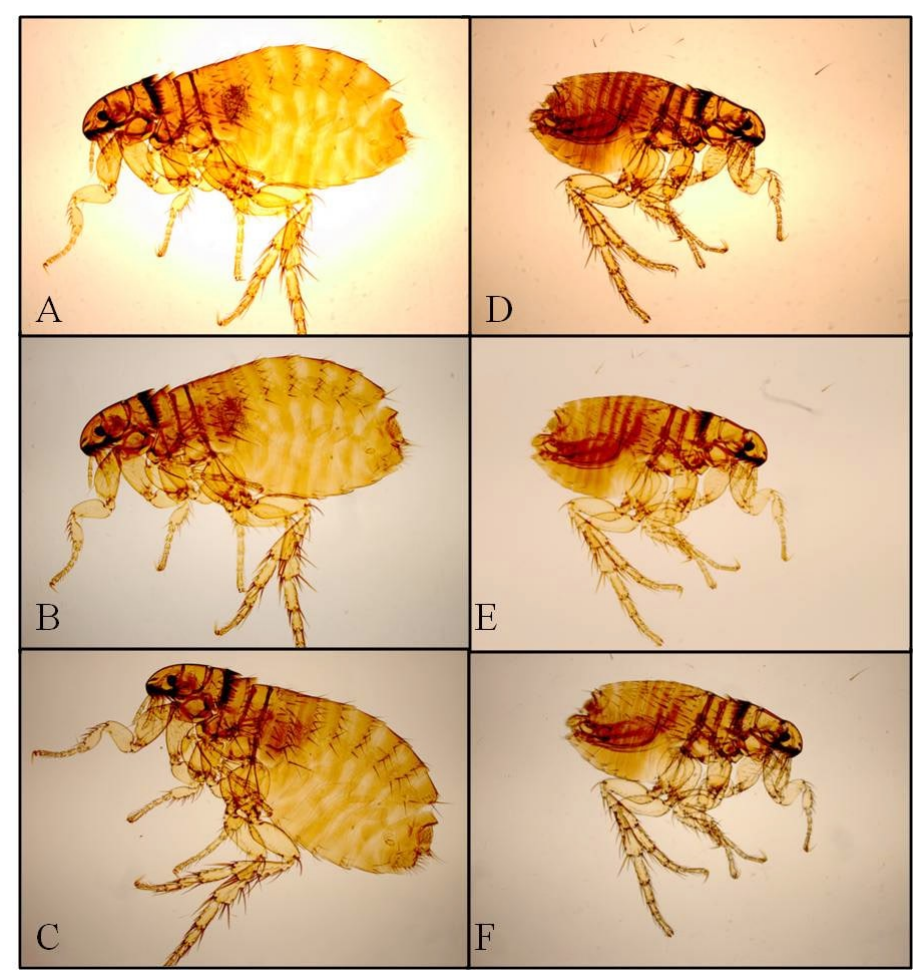

Figura 05. A a C) Lâmina 17, montagem em Xilol e bálsamo do Canadá. Objetiva de 4x. A) Imediatamente após a montagem; B) 08 dias após a montagem; C) 10 meses após a montagem. D a F) Lâmina 19, montagem em Xilol e verniz vitral. Objetiva de 4x. D) Imediatamente após a montagem; E) 08 dias após a montagem; F) 10 meses após a montagem.

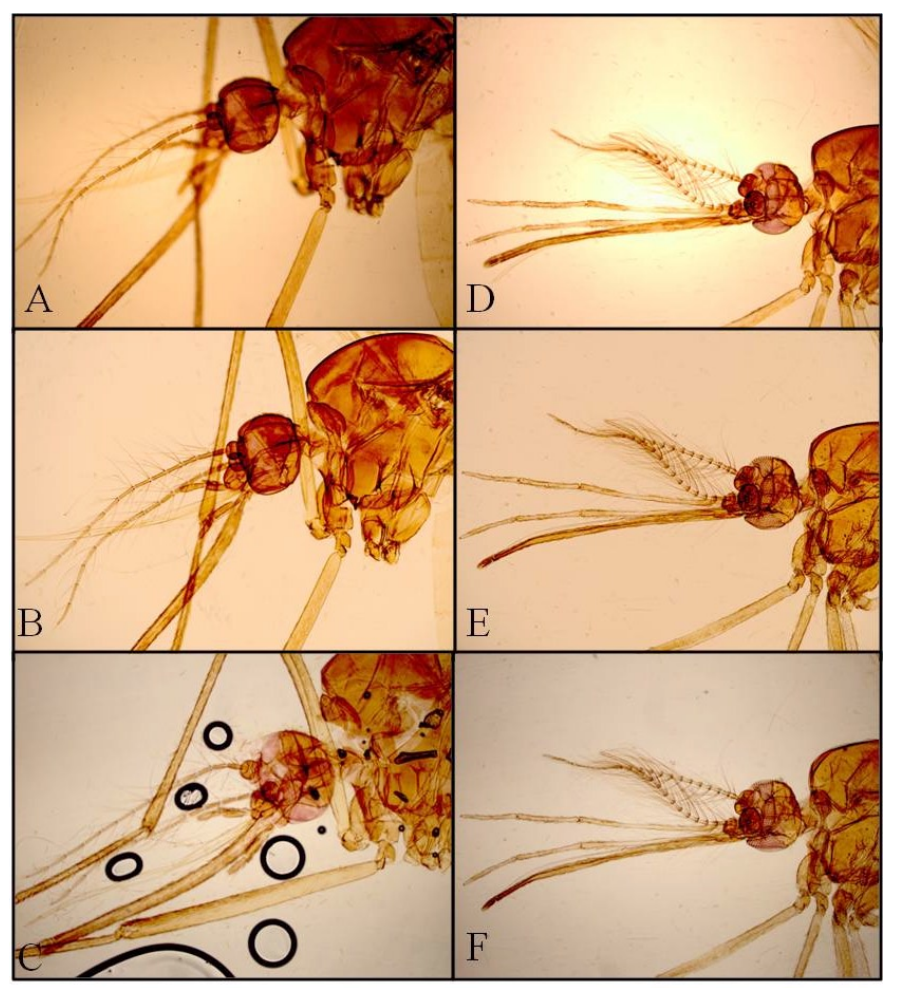

Figura 04. A a C) Lâmina 26, montagem em Xilol e Bálsamo do Canadá. Objetiva de 4X. A) 05 dias após a montagem; B) 45 dias após a montagem; C) 10 meses após a montagem. D a F) Lâmina 27, montagem em Xilol e Verniz Vitral. Objetiva de 4x. D) Imediatamente após a montagem; E) 45 dias após a montagem; F) 10 meses após a montagem. Notem-se a presença de bolhas de ar no quadro C, o vazamento do bálsamo do Canadá permitiu a entrada de ar no espaço entre a lâmina e a lamínula.

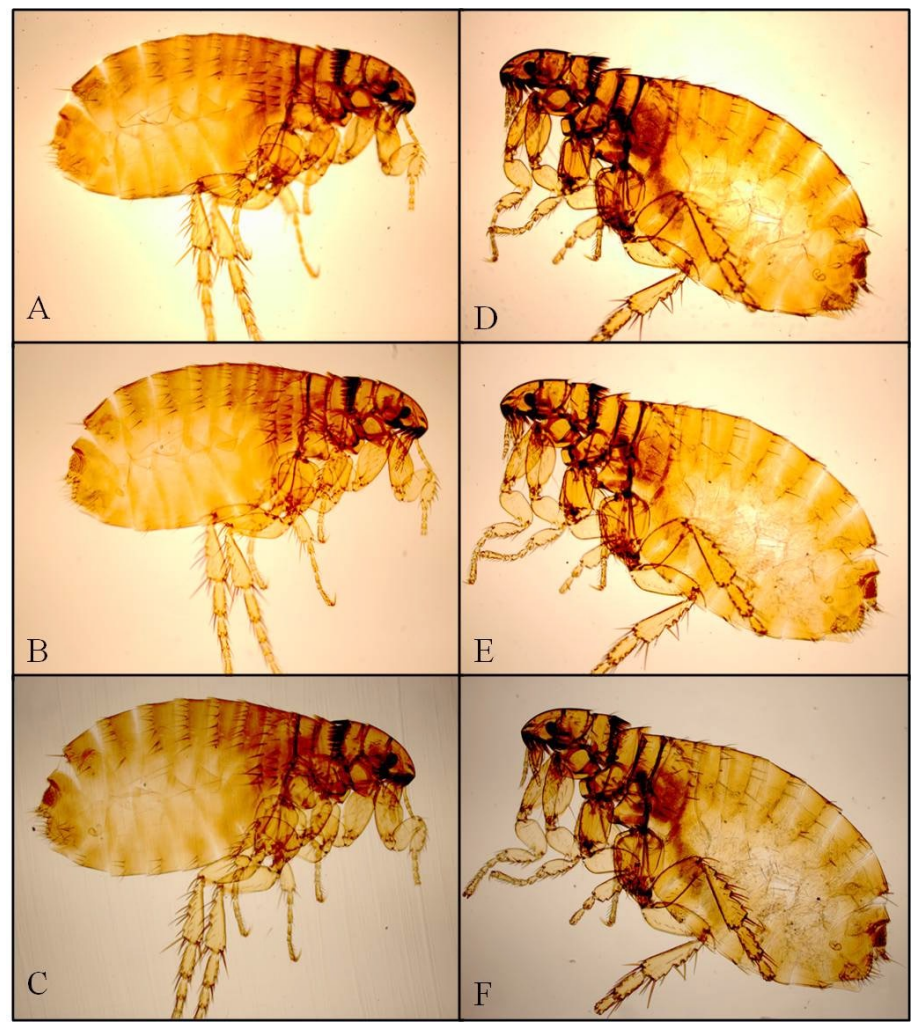

Figura 06. A a C) Lâmina 28, montagem em solvente e bálsamo do Canadá. Objetiva de 4x. A) Imediatamente após a montagem; B) 45 dias após a montagem; C) 10 meses após a montagem. D a F) Lâmina 30, montagem em solvente e verniz vitral. Objetiva de 4x. D) Imediatamente após a montagem; E) 45 dias após a montagem; F) 10 meses após a montagem. 
solvente se mostrou um pouco mais agressivo à estrutura dos insetos, danificando partes da quitina.

O xilol também se mostrou eficiente quando utilizado em conjunto com o material alternativo para a efetiva montagem da lâmina, o verniz vitral incolor.

Avaliando os resultados aqui expostos concluímos que os materiais alternativos aqui testados, em sua maioria, apresentaram resultados favoráveis a sua utilização, com destaque para o verniz vitral incolor que substitui com eficiência o bálsamo do Canadá e do óleo de imersão para microscopia em substituição ao creosoto.

Assim, é possível utilizar tais materiais, sem grandes prejuízos à observação das estruturas dos insetos em microscopia óptica, a exceção do solvente para artesanato, que mostrou ser agressivo demais à quitina dos insetos.

Cabe ainda citar que as montagens em óleo de imersão e verniz vitral incolor oferecem maior facilidade no manuseio, possuem um custo total mais baixo e menor índice de toxidez, além de apresentarem maior translucidez na lâmina montada, pois a característica "incolor" de ambos permite total transparência, sendo quase imperceptível a presença do produto no meio de montagem. Conferindo, assim, maior vantagem sobre os produtos tradicionais.

Nota: Considerando que o óleo de imersão é um óleo mineral, poderia ser testado o uso de óleo mineral comercializado em farmácias, para a montagem de insetos, barateando ainda mais o custo da técnica e a acessibilidade aos reagentes.

\section{AGRADECIMENTOS}

À FAPERJ pelo auxílio financeiro.

\section{REFERÊNCIAS}

Cardoso, P. G.; Souza, M. B.; Sanavria, A.; Meira, A. M.; Meródio, J. C., 2009. Flebótomos de áreas com ocorrências de casos humanos de leishmaniose tegumentar americana no Município de Seropédica, Estado do Rio de Janeiro. Revista da Sociedade Brasileira de Medicina Tropical. 42:146-150.

Cerqueira, N.L. 1943. Um novo meio para montagem de pequenos insetos em lâminas. Memórias do Instituto Oswaldo Cruz. 39: 37.

Costa, K.N.S., Pinheiro, I.O.P., Calaznas, G.T., do Nascimento, M.S. 2007. Avaliação dos riscos associados ao uso do xilol em laboratórios de anatomia patológica e citologia. Revista Brasileira de Saúde Ocupacional. 32:50-56

Consoli, R.A.G.B., \& R. L. Oliveira. 1994. Principais Mosquitos de Importância Sanitária no Brasil. Rio de Janeiro. Editora Fiocruz. 228 p.

Palma, R.L. 1978. Slide-mounting of Lice: a detailed description of the Canada Balsam technique. The New Zealand Entomologist. 6:432-436.

Paiva, J.G.A., Fank-de-Carvalho, S.M, Magalhães, M.P., Ribeiro, D.G., 2006. Verniz vitral incolor 500ß: uma alternativa de meio de montagem economicamente viável. Acta Botânica Brasílica. 20:257-264.

\section{ANEXO I}

Ficha Química dos Produtos Químicos mais Utilizados Atualmente para Montagem de Insetos em Lâminas Para Visualização Em Microscopia Óptica

\section{XILOL}

Nome químico: Xilol

Sinônimos ou outras designações: Xileno, Dimetilbenzeno, Metiltolueno.

Fórmula química: $\mathrm{C}_{6} \mathrm{H}_{4}\left(\mathrm{CH}_{2}\right)_{2}$

Características: líquido incolor, insolúvel em água e miscível em etanol, éter e outros solventes orgânicos, de odor característico, nocivo e inflamável.

Classificação: Nocivo / Inflamável

$\begin{array}{cl}\text { Indices: Saúde } & 2-\text { moderado } \\ \text { Flamabilidade } & 3-\text { severo } \\ \text { Reatividade } & 0 \text { - nenhum } \\ \text { Corrosividade } & 2-\text { moderado }\end{array}$

Equipamento a ser usado em laboratório: luvas, óculos e casaco protetores.

Perigos à saúde humana: danoso ou fatal se for ingerido. Afeta o sistema nervoso central. Causa severas irritações na pele, olhos e trato respiratório. Pode ser danoso se absorvido pela pele.

\section{Efeitos potenciais à saúde humana:}

Inalação

Causa irritação ao nariz e garganta. Em altas concentrações pode causar náusea, vômito, dores de cabeça e severas dificuldades de respiração, dores e tosse. Vapor em alta concentração é anestésico.

\section{Ingestão}

Causa sensação de queimadura na boca e estômago, náusea, vômito e salivação. Pequenas quantidades nos pulmões podem causar severas hemorragias com danos pulmonares ou morte.

Contato com a pele

Causa perda da camada natural de óleo na pele e freqüentemente resulta em dermatites.

Contato com os olhos

Os vapores causam irritação. Pode causar queimadura na córnea e danos nos olhos.

Exposição crônica

Inalação crônica pode causar dor de cabeça, perda do apetite, nervoso e palidez. Contato repetido ou prolongado pode causar rachaduras na pele. Repetida exposição pode causar danos na medula óssea, causando baixa quantidade de células no sangue. Pode prejudicar o fígado e os rins.

Agravo das condições pré- existentes

Pessoas com desordens de pele ou problemas nos olhos, com falhas no fígado, rim, sangue ou função respiratória falha podem ser mais suscetíveis aos efeitos da substância.

O uso freqüente do xilol em laboratórios de ensino e pesquisa, análises clínicas e patológicas pode causar agravos à saúde dos trabalhadores expostos.

Informações Ambientais: A presença do xilol na rede de esgoto pode ocasionar explosão devido ao acúmulo de vapores na tubulação, além de ser tóxico para a vida aquática.

Seus vapores são prejudiciais ao meio ambiente. Produto tóxico à vida aquática, mesmo em baixas concentrações. Pode transmitir qualidades indesejáveis à água prejudicando seu uso. Pode afetar o solo e, por percolação, degradar a qualidade das águas do lençol freático.

\section{Hidróxido de Potássio (Potassa Cáustica)}

Nome Químico: Hidróxido de Potássio.

Sinônimos ou outras designações: Potassa Cáustica, Hidróxido de Potássio em escamas.

Fórmula Química: $\mathrm{KOH}$

Características: A substância química hidróxido de potássio é um produto inorgânico, ocorrendo na forma de lentilhas brancas. Solúvel em água e levemente solúvel em álcool etílico. Sem odor. Não volátil.

Classificação: Corrosivo

Indices: Saúde

$\begin{array}{ll}\text { Flamabilidade } & 3 \text { - }- \text { - não perigoso } \\ \text { Reatividade } & 2-\text { moderado } \\ \text { Corrosividade } & 3 \text { - sério }\end{array}$

Efeitos potenciais à saúde humana: O produto é um forte álcali, altamente higroscópico, e perigoso quando não for manuseado corretamente.

Irritações - o produto, na forma em pó, névoas ou neblina, pode ser irritante para os olhos, pele e vias respiratórias. 


\section{Efeitos adversos à saúde humana:}

\section{Inalação}

Inalação de pó ou névoa pode causar dano a todas as vias respiratórias.

Ingestão

Podem provocar queimaduras e perigo de perfuração na garganta, estômago e esôfago.

Contato com a pele

Pode ser destrutivo a todos os tecidos humanos com que entra em contato, produzindo severas queimaduras.

Contato com os olhos Pode causar dano severo e/ou permanente.

Principais Sintomas: os efeitos do Hidróxido de Potássio sobre a saúde humana são, em sua maioria, imediatos e provocam sintomas claros, como queimaduras e necrose de tecidos vivos.

Informações Ambientais: Quando derramado em condições secas, pode ser recolhido com pá para descarte. Deve-se evitar a geração de líquido contaminado que poderá atingir mananciais. Produto de difícil degradação.

\section{Balsamo do Canada}

Nome Químico: Bálsamo do Canadá.

Fórmula Química: Não aplicável. Produto Natural de composição variável.

Características: Líquido viscoso, na cor marrom escuro, com odor aromático característico e sabor forte e amargo persistente. Consiste de extrato vegetal. É solúvel em álcool etílico, clorofórmio e ácido acético glacial com alguma opalescência. Insolúvel em água e azeite de oliveira. Parcialmente solúvel em éter etílico e éter de petróleo.

Classificação: Inflamável

Perigos à saúde humana: Não ingerir. Evitar contato com a pele, os olhos e vias respiratórias. Em caso de ingestão provocar vômito e recorrer a um médico.

Manuseio e armazenamento: O manuseio e a armazenagem da substância deve se dar em condições adequadas, evitando-se a contaminação do produto. É recomendável a utilização de luvas e máscaras durante o manuseio por tempo prolongado.

Informações Ambientais: Dados quantitativos sobre os efeitos ecológicos deste produto não estão disponíveis.

\section{Fenol}

Nome Químico: Fenol

Sinônimos ou outras designações: Ácido Fênico

Fórmula Química: $\mathrm{C}_{6} \mathrm{H}_{5} \mathrm{OH}$ (variação: $\mathrm{C}_{6} \mathrm{H}_{6} \mathrm{O}$ )

Características: A substância química fenol é um produto orgânico, ocorrendo na forma de sólido como uma massa cristalina incolor. Solúvel em álcool etílico, água, éter etilico, dissulfeto de carbono, glicerol e clorofórmio.

Classificação: Tóxico

Indices: Saúde

$$
3 \text { - sério }
$$$$
\text { Flamabilidade } 2 \text { - moderado }
$$$$
\text { Reatividade } \quad 1 \text { - leve }
$$$$
\text { Contato 4-extremo }
$$

Equipamento a ser usado em laboratório: Luvas, óculos e casaco protetores.

Perigos à saúde humana: Tóxico em contato com a pele e por ingestão. Provoca queimaduras.

Efeitos potenciais à saúde humana: Corrosivo! É irritante das membranas mucosas. Pode ser fatal se ingerido, inalado ou absorvido pela pele. Causa severas queimaduras. Afeta o sistema nervoso central, fígado e rim.

Inalação

Provoca dispnéia e tosse. A absorção sistêmica provoca danos ao fígado, rins e sistema nervoso central.

Ingestão

Provoca queimaduras intensas da boca e da garganta, dor abdominal acentuada, cianose, fraqueza muscular e coma. Podem ser observados tremores e contrações musculares. A morte pode advir por parada respiratória.
Pode provocar desde um eritema até necrose e gangrena dos tecidos, dependendo do tempo de contato e da concentração das soluções. O maior perigo do fenol é a habilidade de penetrar rapidamente na pele, causando severas lesões que podem ser fatais.

Contato com os olhos

Extremamente irritante para os olhos. Pode provocar inchaço da conjuntiva; a córnea torna-se branca e muito dolorida, podendo ocorrer perda de visão.

Informações Ambientais: Esta substância é tóxica para a vida aquática. A mobilidade é muito alta. Produto levemente solúvel, que permanece na superfície d'água.

O Fenol pode causar mutações (alterações genéticas). Desta forma pode apresentar um risco de câncer.

\section{Creosoto}

Nome Químico: Creosoto de Faia

Fórmula Química: Não definida

Grupo químico: mistura complexa, contendo principalmente hidrocarbonetos poliaromáticos, ( $\left.\mathrm{PAH}^{\prime} \mathrm{s}\right)$, heterocíclicos e fenóis.

Características: A substância química ocorre na forma de líquido oleaginoso, cor amarelo, pardo pálido ou quase incolor. Escurece com a idade ou com exposição à luz. Solúvel em metanol e acetona. Muito ligeiramente solúvel em água fria.

Classificação: Tóxico / Corrosivo

$\begin{array}{cl}\text { Indices: Saúde } & 3-\text { sério (veneno) } \\ \text { Flamabilidade } & 1-\text { leve } \\ \text { Reatividade } & 1-\text { leve } \\ \text { Contato } & 3-\text { sério }\end{array}$

Equipamento a ser usado em laboratório: Óculos, avental, capela e luvas apropriadas.

Perigos à saúde humana: Tóxico por ingestão. Risco de graves lesões oculares. Pode causar sensibilização por inalação e em contato com a pele.

Efeitos potenciais à saúde: "Pode causar câncer".

Inalação

Pode causar problemas respiratórios, como irritação das mucosas, dores de cabeça, desorientação, fraqueza, coma morte.

Ingestão

Tóxico! Distúrbios gastrointestinais e dores abdominais. Vômito e náusea

Contato com a pele

Causa irritação, dor, vermelhidão e queimaduras. Pode haver reação foto tóxica.

Contato com os olhos

Causa irritação, vermelhidão e dor.

Exposição crônica

A exposição crônica através de qualquer rota pode resultar em danos ao sistema respiratório, ao sistema nervoso central, colapso circulatório, coma e morte. Pode causar câncer.

Agravo das condições pré-existentes

As pessoas sensíveis devem evitar contato com o produto.

Informações Ambientais: Altamente tóxico para organismos aquáticos. Não solúvel em água. A bioacumulação do Creosoto é significativa.

Produtos de sua decomposição: Pode formar vapores tóxicos quando decomposto. Monóxido de Carbono e Dióxido de Carbono.

Obs: O ar ambiente do local onde se trabalha com Óleo Creosoto deve ser monitorado diariamente.

O limite máximo de voláteis do alcatrão da hulha permitido no ar é de 0,2 miligramas por metro cúbico $\left(\mathrm{mg} / \mathrm{m}^{3}\right)$. 
Ficha Química dos Produtos Químicos Propostos como

Alternativos para Montagem de Insetos em LÂminas Para Visualização em Microscopia ÓPTiCa

\section{a) Óleo De IMERsão (Merckß)}

Nome Químico: Óleo de Imersão para Microscopia. Fórmula Química: $\mathrm{C}_{14} \mathrm{H}_{12} \mathrm{O}_{2}$ (A preparação contém compostos orgânicos).

Características: A substância é apresentada na forma de líquido oleaginoso, na cor amarelo claro, odor característico. Classificação: Tóxico

Perigos à saúde humana: Prejudicial se ingerido, podendo causar náusea, vômito e diarréia. Se inalado causa irritação do trato respiratório. Causa irritações leves se em contato com a pele, com sensibilização em pessoas predispostas.

Equipamento a ser usado em laboratório: As roupas de proteção devem ser selecionadas especificamente para o local de trabalho; proteção respiratória (apenas durante a geração de vapores); proteção para olhos.

Efeitos potenciais à saúde humana: Se absorvido em grande quantidade causa desordem cardiovascular, agitação, espasmos, ataxia (comprometimento da coordenação motora).

Informações Ambientais: Dados quantitativos sobre os efeitos ecológicos deste produto ainda não estão disponíveis. Evitar despejos em água ou solo.

b) VeRNiz Vitral INCOLOR 500® (Acrilex)

Nome Químico: Verniz Vitral (incolor)

Tipo de produto: Preparado

Natureza Química: Resina Alquídica Modificada

Componentes Químicos:

Resina Alquídica (Sólidos) / 35 - 40 \%

Xilenos (orto, meta, para) / $20-30 \%$

Éter Monobutílico de Etilenoglicol / 20 - $30 \%$

Características: Líquido transparente, odor característico.

Classificação: Nocivo / Inflamável.

Perigos à saúde humana: Nocivo. Os vapores deste produto podem irritar os olhos, as membranas mucosas e a pele. Em concentrações elevadas os mesmos podem provocar narcose. A ingestão pode causar fortes dores abdominais e irritação gástrica.

Equipamento a ser usado em laboratório: Em baixas

\section{Como citar este artigo:}

F. Huber \& F.H. Reis, 2011. Técnica Alternativa para Montagem de Insetos em Lâminas Permanentes para Visualização em Microscopia Óptica. EntomoBrasilis, 4(1): 13-19. www.periodico.ebras.bio.br/ojs concentrações, usar respirador com filtro químico para vapores orgânicos; usar luvas de PVC ou outras resistentes a solventes orgânicos; nas operações onde possam ocorrer projeções ou respingos, recomenda-se o uso de óculos de segurança ou protetor facial.

Efeitos potenciais à saúde humana: Pode causar dor de cabeça, náuseas, tonteiras e confusão mental.

Informações Ambientais: Moderadamente volátil. Pode contaminar lençóis freáticos. Como na maioria dos hidrocarbonetos, sua presença na água pode transmitir qualidades indesejáveis à água, prejudicando seu uso.

c) Solvente Comercial para Artesanato Vitral (Acrilex®)

Nome Químico: Solvente

Tipo de produto: Preparado

Natureza Química: Mistura de hidrocarbonetos e glicóis

Componentes Químicos:

Xilenos (orto, meta, para) / $49-51 \%$

Hidrocarbonetos aromáticos / 0,5-1\%

Éter Monobutílico de Etilenoglicol / 49 - $51 \%$

Características: Líquido incolor, odor característico.

Classificação: Nocivo / Inflamável.

Perigos à saúde humana: Produto nocivo. Pode causar dor de cabeça, náuseas, tonteiras e confusão mental. Irritação nas vias aéreas superiores. Moderadamente irritante para a pele. Irritante para os olhos.

Equipamento a ser usado em laboratório: Em baixas concentrações, usar respirador com filtro químico para vapores orgânicos; luvas impermeáveis. Nas operações onde possam ocorrer projeções ou respingos, recomenda-se o uso de óculos de segurança ou protetor facial.

Efeitos potenciais à saúde humana: Nocivo. Os vapores deste produto podem irritar os olhos, as membranas mucosas e a pele. Em concentrações elevadas os mesmos podem provocar narcose. A ingestão pode causar fortes dores abdominais e irritação gástrica. Pode causar dor de cabeça, náuseas, tonteiras e confusão mental.

Informações Ambientais: Moderadamente volátil. Pode contaminar lençóis freáticos. Como na maioria dos hidrocarbonetos, sua presença na água podetransmitir qualidades indesejáveis à água, prejudicando seu uso.

Recebido em: 08/08/2010

Aceito em: 19/10/2010

$$
* * * * * * * * * * * * *
$$
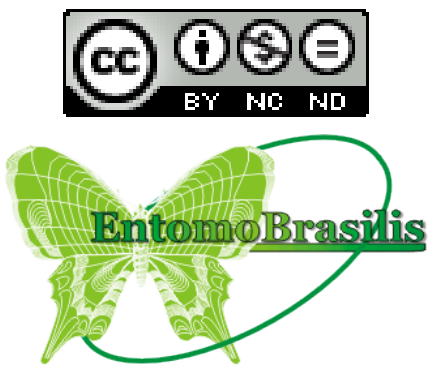